\section{Rol epidemiológico de Oligoryzomys longicaudatus (ratón colilargo) en tres enfermedades zoonoticas en Chile}

\section{Epydemiologic role of Olygoryzomys longicaudatus (long tail rodent) in three zoonotics diseases in Chile}

\section{Señor Editor:}

Oligoryzomys longicaudatus, es un roedor nativo de la familia Cricetidae que tiene una extensa distribución geográfica en el país, desde la IV Región por el norte hasta Tierra del Fuego por el sur, en zonas de matorral y bosque. Es una importante especie de las comunidades de pequeños mamíferos chilenos, con una característica ecológica que es su gran movilidad y extenso ámbito de hogar ${ }^{5}$. Además, es una especie oportunista que se ha visto beneficiada por el proceso de fragmentación de hábitats que ha ocurrido en el país y que se desplaza desde los bosques a los agro-ecosistemas durante el verano, donde se ubica en la vegetación herbácea y arbustiva que crece en los bordes de los potreros y cultivos ${ }^{1}$. Pero lo más importante desde el punto de vista de la salud humana, es el rol epidemiológico que cumple, al ser activo en tres importantes enfermedades infecciosas: Leptospirosis, Hanta virus y enfermedad de Lyme. Lo primero fue el hallazgo de leptospiras en análisis serológicos efectuados en la zona de Valdivia ${ }^{6}$. En segundo lugar ha sido el único reservorio confirmado del virus Hanta en Chile $^{3}$ y recientemente se ha descubierto que es el hospedero competente de la garrapata Ixodes stilesi que junto con el pequeño ciervo nativo $P u d u$ puda son claves en el ciclo de la Borrelia chilensis. Esta espiroqueta es responsable de la enfermedad de Lyme, que ha sido descrita recientemente en Chile ${ }^{2}$. La garrapata se alimenta de sangre de su huésped y cambia de estado en su ciclo de vida moviéndose a otro huésped. Así, estados inmaduros, larvas y ninfas, son específicos de pequeños mamíferos, roedores silvestres, y las garrapatas adultas prefieren los ciervos. El ciclo de la garrapata está estrechamente relacionado con las condiciones ambientales asociadas a vegetación densa que mantenga humedad sobre $70 \%$ y temperaturas de alrededor de $15{ }^{\circ} \mathrm{C}^{4}$. Estas condiciones se encuentran en el sur de Chile donde también coexisten el roedor silvestre $O$. longicaudatus y el ciervo $P$. puda lo que es confirmado con el hallazgo de la nueva especie, Borrelia chilensis en la garrapata Ixodes stilesi en el ciclo natural con el roedor Oligoryzomys longicaudatus y el pequeño ciervo nativo Pudu puda.

La aparición de la zoonosis enfermedad de Lyme, está en cierto modo asociada al gran impacto de la actividad antrópica aplicada sobre los bosque del sur, para incorporar suelos a la agricultura aumentando las praderas con árboles, donde Borrelia chilensis, el patógeno y sus vectores encuentran el hábitat adecuado.

Es interesante notar que si bien están presentes todos los huéspedes del ciclo de Borrelia chilensis, y una mayor cercanía del ser humano al entorno natural, no hay muchos casos clínicos diagnosticados. Esto puede ser parcialmente explicado por la importante disminución de ciervo enano, Pudu puda, que está estrechamente asociada a la desaparición del bosque nativo. Sin embargo, aunque la incidencia de la enfermedad es baja, debe incentivarse la búsqueda activa de casos clínicos sobre todo en la zona sur y sur austral.

Roberto Murúa Med.Vet. MSc. Departamento de Ciencias Agronómicas y Recursos Naturales, Facultad de Ciencias Agropecuarias y Forestales, Universidad de la Frontera. Teтuco, Chile.

\section{Referencias}

1. Barrera K, Murua R. Nuevo desafío en Salud Pública: Presencia de reservorios de Hanta, Oligoryzomys longicaudatus y Rattus spp., en aéreas de borde en praderas del sur de Chile. Sustainability, Agri Food and Environmental Research 2015; 3(3): 33-46.

2. Ivanova LB, Tomova A, González-Acuña D, Murua R, Moreno CX, Hernández C, et al. Borrelia chilensis, a new member of the Borrelia burgdorferi sensu lato complex that extends the range of this genospecies in the Southern Hemisphere. Environ Microbiol 2014; 16 (14): 1064-80.

3. Medina RA, Torres-Pérez F, Galeno H, Navarrete M, Vial PA, Palma RE, et al. Ecology, Genetic Diversity and Phylogeographic Structure of Andes Virus in Humans and Rodents in Chile. J Virol 2008; 83: 2446-51.

4. Madigan JE, Teitler J. Borrelia burgdorferi borreliosis. J Am Vet Med Assoc J 192: 892-96.

5. Murua R, González LA, Meserve P. Population ecology of Oryzomys longicaudatus phillippi (Rodentia: Cricetidae) in southern Chile. J Anim Ecology 1986; 55: 231-93.

6. Zamora J, Murua R. Infecciones de Leptospira en roedores silvestres. Comunicación preliminar. Arch Med Vet 1976; 8: 120-1.

Correspondencia a:

Roberto Murúa

Casilla 54-D, Temuco-Chile.

roberto.murua@ufrontera.cl 